\title{
Ectopic third molars in the sigmoid notch: etiology, diagnostic imaging and treatment options
}

\author{
Marcel Hanisch", Leopold F. Fröhlich and Johannes Kleinheinz
}

\begin{abstract}
Background: The etiology of ectopic third molars located in the sigmoid notch of the mandible is unclear. Only a few cases have been reported. The aim of this article is to discuss the etiology as well as treatment options and diagnostic imaging techniques.

Methods: A PubMed and Medline search of the literature from 1965 to 2015 to ectopic third molars in the mandibular notch was performed. Furthermore, a clinical case provided by the authors is reported.

Results: Among the eight reviewed cases, two male and six female patients were affected that ranged from 25 to 62 years of age (mean 48.4). Pain and swelling in the preauricular region or trismus but also the absence of symptoms was reported. Only in two of the summarized articles an extra-oral access for the removal of the tooth was used. The etiology seems to be individually different, however dentigerous cysts and chronic inflammation seem to play an important role in their appearance. While previous diagnostic reports described two-dimensional diagnostic imaging, currently the three-dimensional imaging is common for preoperative surgical planning with respect to removing ectopic molars.
\end{abstract}

Conclusions: Ectopic third molars in the mandible are a rare condition. The etiology seems to be individually different. Nowadays, three-dimensional imaging is common for preoperative surgical planning.

Keywords: Dentigerous cyst, Ectopic third molar, Ectopic tooth, Mandibular notch, Sigmoid notch

\section{Background}

Ectopic molars in the mandible are rare cases and the etiology of this condition is still unclear [1]. Ectopic third molars of the mandible have been described in the condylar region, the coronoid process, the ascending ramus and the sigmoid notch. A review by Wang et al. indicated only 13 reported cases in the literature depicting ectopic molars in the ramus region during a period of 30 years [2]. The surgical excision of third molars is one of the most common outpatient surgeries [3], whereas the removal of ectopic molars seem to be an unusual surgical intervention. Preoperative diagnosis is based on clinical findings and diagnostic X-ray examination [4]. In the present paper, we review the literature of all cases describing ectopic third molars found in the

* Correspondence: marcel.hanisch@ukmuenster.de

Department of Cranio-Maxillofacial Surgery, University Hospital Münster,

Albert-Schweitzer-Campus 1, Gebäude W 30, Münster D-48149, Germany mandibular sigmoid notch region, which have been reported over a period of 50 years from 1965 to 2015. Subsequently, we add to this summary our own experience by presenting a new case with an ectopic third molar in the sigmoid notch.

\section{Methods}

A clinical case provided by the authors is reported. Furthermore, a literature search in PubMed and Medline databases was achieved by using the following $\mathrm{MeSH}$ terms: "sigmoid notch" OR "mandibular notch" AND "ectopic tooth" OR "third molar". Inclusion criteria were international cases of ectopic third molars in the sigmoid notch, which have been reported in English or native language from 1965 to 2015. 


\section{Results}

From 1965 to 2015 only eight cases with ectopic third molars that occurred in the sigmoid notch of the mandible have been reported. In addition to six case reports which were written in English language [5-10], two cases that were presented in native language by an Italian and a Japanese group [11, 12], respectively, were also included. Clinical and radiological features of these eight cases are summarized in Table 1.

\section{Gender and age prevalence}

Six female patients and two male patients were diagnosed with ectopic molars in the sigmoid notch. The age ranged from 25 to 62 , with an average age of 48.4 years.

\section{Clinical symptoms}

As clinical symptoms the eight reported cases describes pain [8], swelling [7], trismus [5], discomfort of the mucosa [10] as well as combinations of these symptoms $[11,12]$ or no symptoms $[6,9]$. The clinical features of the eight reported cases are summarized in Table 2.

\section{Treatment}

Treatment was described in all cases except one [8]. Granite et al. reported periodic radiographic examination [6], Giordano et al. indicated denied treatment by the patient [11] whereas three authors referred their patients to intraoral access and extraction of the ectopic molar under general anesthesia $[7,9,10]$. Only two cases described extra-oral surgical access for the extraction of the ectopic molar $[5,12]$. In detail, submandibular access was selected in both reports.

\section{Association with cystic lesions}

Cystic lesions were described in four cases $[5,7,9,12]$. Giordano et al. described encircling radiolucency [11].
Adachi et al. also reported encircling radiolucency which was diagnosed pathologically as granulation tissue [10]. One report referred to an area of sclerotic bone surrounding the tooth [6] whereas Balan did not describe any cystic lesion or other abnormalities which could be detected in the radiologic image [8].

\section{Diagnostic imaging}

Diagnostic imaging techniques reports from 1992 to 1965 described lateral oblique radiographs $[7,8,11,12]$, a panoramic radiograph [6], or posteroranterior and lateral jaw projection $[5,11,12]$. Diagnostic imaging by three-dimensional methods, in addition to a twodimensional panoramic radiograph, was only reported by Fidink et al. and Adachi et al. in 2015 [9, 10].

\section{Case presentation}

A 51 year-old male was referred to our Clinic of CranioMaxillofacial Surgery by his dentist. The patient described pain in the preauricular region for a few days. The panoramic radiograph revealed lower right third molar being dislocated in the sigmoid notch associated with a radioluscent lesion (Fig. 1). In addition, the panoramic radiograph offered generalized periodontitis and an impacted third molar surrounded with a radioluscent lesion on the left side of the mandible. Unfortunately, no earlier radiographic images of the patient were available for comparing the development of the ectopic molar. Clinical intra- and extraoral inspection disclosed no further inflammation signs like swelling, trismus, fever or redness. Also signs of chronic inflammation like fistula did not appear. Cone beam scans (CT) showed the impacted tooth with cranial-dorsal directed roots and bone apposition in the sigmoid notch (Figs. 2, 3, 4). A radiolucent cystic lesion was extending from the pericoronary region of the tooth to the dental arch. The

Table 1 Clinical and radiological features of ectopic molars in the sigmoid notch reported from 1965 to 2015

\begin{tabular}{|c|c|c|c|c|c|}
\hline Author & Gender & Age & Symptoms & Surgical access & Radiology \\
\hline Traiger J. et al. 1965 [5] & female & 47 & $\begin{array}{l}\text { firm, hard swelling of the } \\
\text { side of the face }\end{array}$ & $\begin{array}{l}\text { extraoral, general } \\
\text { anesthetic }\end{array}$ & $\begin{array}{l}\text { posteroanterior and lateral jaw projection; encircling } \\
\text { radiolucency }\end{array}$ \\
\hline $\begin{array}{l}\text { Giardino et al. } 1966[11] \\
\text { (Article in Italian) }\end{array}$ & female & 62 & $\begin{array}{l}\text { trismus, sporadic pain } \\
\text { praeauricular }\end{array}$ & none & $\begin{array}{l}\text { posteroranterior roentgenogram, lateral oblique } \\
\text { radiograph; encircling radiolucency }\end{array}$ \\
\hline $\begin{array}{l}\text { Nishijima et al. } 1976 \text { [12] } \\
\text { (Article in Japanese) }\end{array}$ & female & 60 & $\begin{array}{l}\text { trismus, pain and swelling } \\
\text { in preauricular region }\end{array}$ & $\begin{array}{l}\text { extraoral, general } \\
\text { anesthetic }\end{array}$ & $\begin{array}{l}\text { posteroranterior roentgenogram, lateral oblique } \\
\text { radiograph; encircling radiolucency }\end{array}$ \\
\hline Granite EL et al. 1985 [6] & female & 60 & none & none & panoramic radiograph; area of sclerotic bone \\
\hline Metha DS et al. 1986 [7] & male & 25 & $\begin{array}{l}\text { slowly growing swelling } \\
\text { since } 2 \text { years }\end{array}$ & $\begin{array}{l}\text { intraoral, general } \\
\text { anesthetic }\end{array}$ & lateral oblique radiograph; radiolucent lesion \\
\hline Balan N. 1992 [8] & female & 30 & $\begin{array}{l}\text { pain in preauricular } \\
\text { region }\end{array}$ & not specified & lateral oblique radiograph \\
\hline Fidink Y et al. 2015 [9] & male & 45 & none & $\begin{array}{l}\text { intraoral, general } \\
\text { anesthetic }\end{array}$ & $\mathrm{CT}$, panoramic radiograph; radiolucent lesion \\
\hline Adachi M. et al. 2015 [10] & female & 58 & $\begin{array}{l}\text { discomfort in the left } \\
\text { buccal mucosa }\end{array}$ & $\begin{array}{l}\text { intraoral, general } \\
\text { anesthetic }\end{array}$ & $\mathrm{CT}$, panoramic radiograph; radiolucent lesion \\
\hline
\end{tabular}


Table 2 Clinical Symptoms described in eight reported cases

\begin{tabular}{|c|c|}
\hline \multicolumn{2}{|c|}{ Clinical Symptoms described in the eight reported cases } \\
\hline Symptom & Author \\
\hline Firm hard swelling with complete trismus & Traiger J. et al. 1965 [5] \\
\hline Trismus and sporadic pain preauricularly & $\begin{array}{l}\text { Giardino et al. } 1966 \text { [11] } \\
\text { (Article in Italian) }\end{array}$ \\
\hline $\begin{array}{l}\text { Trismus, pain and swelling in preauricular } \\
\text { region }\end{array}$ & $\begin{array}{l}\text { Nishijima et al. } 1976[12 \\
\text { (Article in Japanese) }\end{array}$ \\
\hline No symptoms & Granite EL et al. 1985 [6] \\
\hline Slowly growing swelling for two years & Metha DS et al. 1986 [7] \\
\hline Pain in the preauricular region & Balan N. 1992 [8] \\
\hline No symptoms & Fidink $Y$ et al. 2015 [9] \\
\hline Discomfort in the left buccal mucosa & Adachi M. et al. 2015 [10] \\
\hline
\end{tabular}

mandibular canal was compressed but covered by a small sclerotic bone (Fig. 1). Under endotracheal general anesthesia, an intraoral access was selected by incising the anterior edge of the mandibular ramus. In order to expose the sigmoid notch, a subperiosteal dissection was done lingually. Because the tooth was completely osseously covered, bone was removed and the tooth was separated with a surgical drill. The cystic lesion was enucleated and sent routinely for pathological analysis to the Department of Pathology, University Hospital Muenster. Microscopic analysis of the specimen showed stratified epithelium, fibrous tissue with lymphocytic-, plasma cell- and granulocytic infiltration of neutrophilic type and chronic inflammation (Fig. 5). Furthermore, all second molars and the third molar on the left mandible have also been removed. No complications occurred in the postoperative phase. Antibiotics were not given during the entire therapy. Subsequently, periodontal therapy will be performed by the patient's dentist.

\section{Discussion}

Up to now, only a few reports of ectopic third molars located in the mandible were recorded in the literature. The etiology of this condition is still unclear but several causes were discussed. Capelli described a correlation between the lack of space between second molar and the ramus mandibulae leading to an ectopic position of the

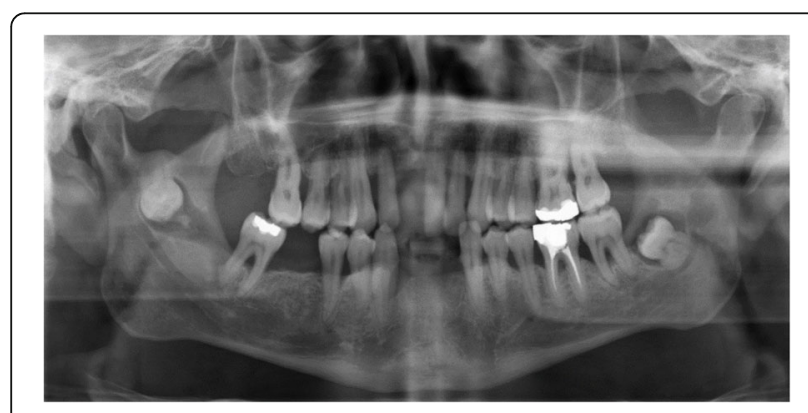

Fig. 1 Panoramic radiograph showing the ectopic third right molar

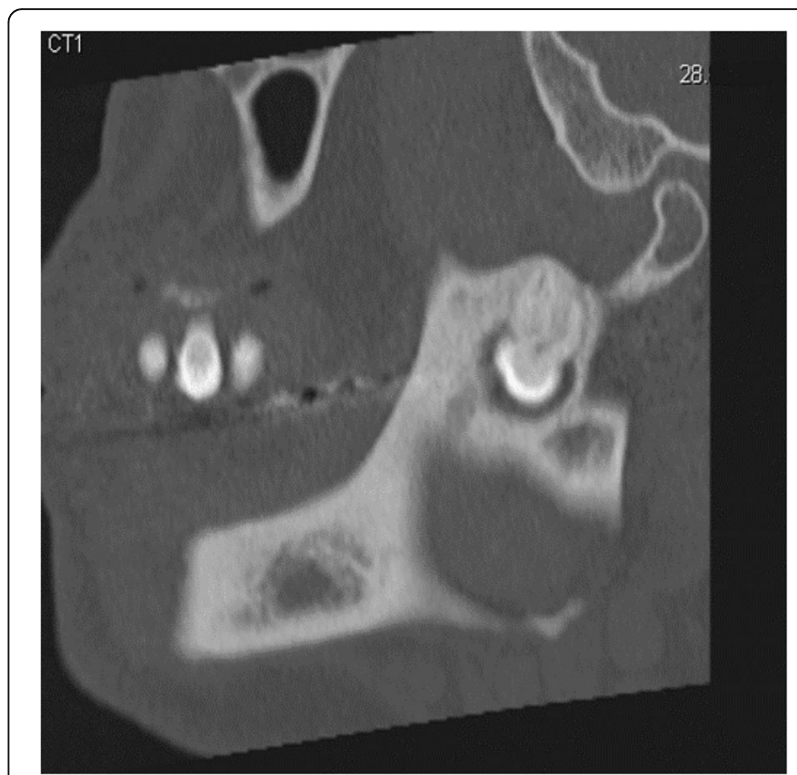

Fig. 2 Sagital cone beam scan showing the impacted tooth with cranial-dorsal directed roots and bone apposition in the right sigmoid notch

impacted third molar [13]. Also a relationship involving the growth of the coronoid process and the ectopic position was suspected whenever the base of the ectopic third molar was embedded in the bony-growth tissue of the coronoid process [14]. Moreover, deviant eruption patterns were also assumed as a primordial deviance of the germ leading to ectopic teeth [15]. These theories may apply to be causative for the individual ectopic molars illustrated in the case reports which were summarized in this review. For the case presented in this article, the theory reported by Thoma in 1958 [16] and several other authors like Stafne [17] seems to apply for the identified ectopic molar. Thoma suspected that the pressure of the cystic fluid was responsible for the

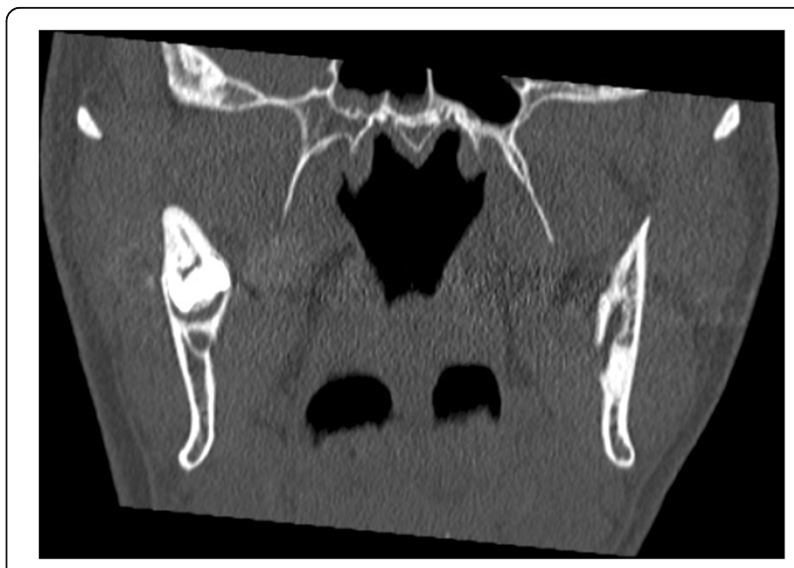

Fig. 3 Coronal cone beam scan showing the impacted tooth with radiolucent cystic lesion superior the inferior alveolar nerve 


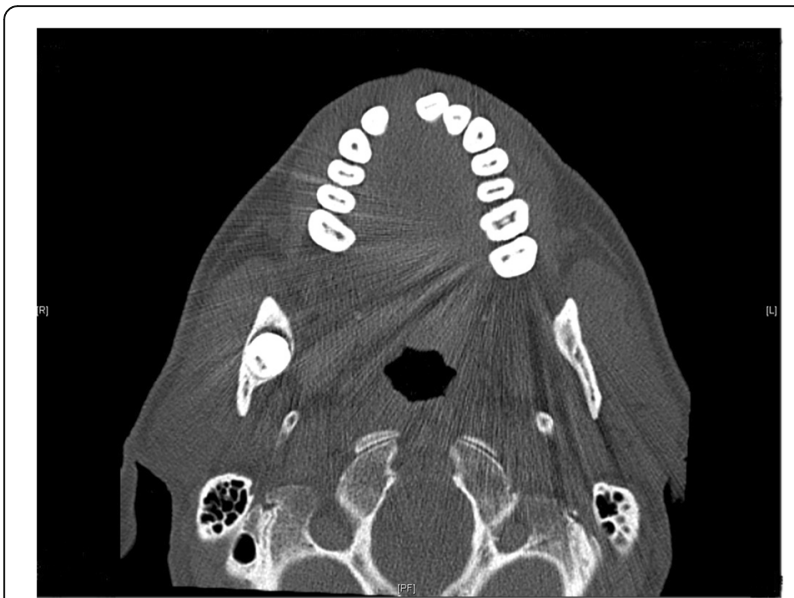

Fig. 4 Axial cone beam scan showing the impacted tooth in the right sigmoid notch

migration of the tooth. In our reported patient, a dentigerous cyst surrounds the crown. In the panoramic radiograph a radiolucent area similar to a "path" that extended from the dental arch to the ectopic molar in the sigmoid notch, appeared. Possibly, this "path" represents the route of migration starting at the dental arch and ending at the sigmoid notch. As inflammations are known to be supporting the expansion of cysts, the periodontitis determined in our patient could serve as an additional factor for the expansion of the cyst, leading to migration of the tooth. The same theory was reported by Adachi et al. which describes "granulation tissue with chronic inflammation around the crown" being etiological to the process of retrograde migration and forcing up the tooth into an ectopic position [10].

In symptomatic patients surgical removal, after a careful preoperative planning, is the recommended treatment [18]. In the past, diagnostic X-ray examinations were mainly implemented by two-dimensional diagnostic

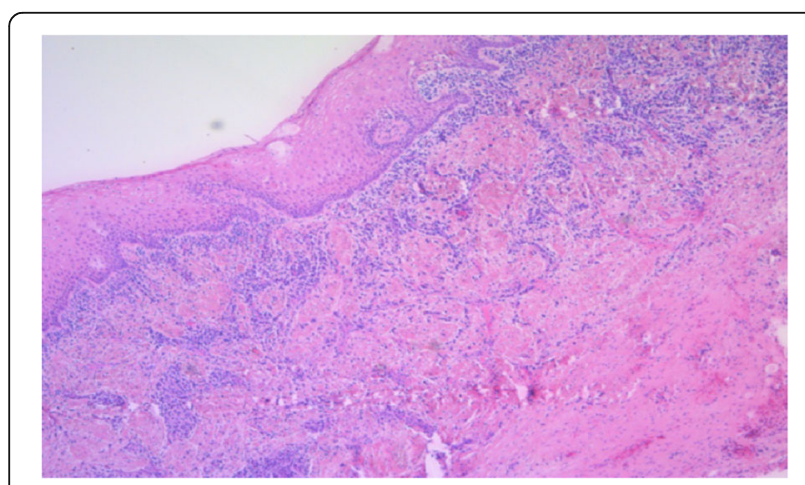

Fig. 5 Microscopic image of the stratified epithelium demonstrating fibrous tissue with lymphocytic-, plasma cell- and neutrophilic granulocyte infiltration, as well as chronic inflammation (PAS, magnification: 100) imaging techniques like panoramic radiograph or lateral jaw projection. Reports about complications during or after the removal of ectopic molars in the sigmoid notch like nerve injury, damage of the mandibular joint, bleeding or infections were not described in the reviewed literature. Ghaeminia et al. illustrated in their study that threedimensional diagnostic imaging, compared to panoramic radiography, can contribute to optimal risk assessment and, as a consequence, allow better surgical planning [19]. Currently, three-dimensional diagnostic imaging techniques are established and can be beneficial in identifying position of the tooth, associated pathology and identifying the position of neurovascular structures [20]. Thus, preoperatively, the appropriate surgical method can be chosen [2].

\section{Conclusions}

Ectopic third molars in the sigmoid notch of the mandible are a rare condition with higher prevalence in women. The etiology seems to be individually different, however dentigerous cysts and chronic inflammation seem to play an important role in their appearance. For planning the surgical entryway, which is mostly selected from intraoral as well as the assessment of operativerisks, three-dimensional diagnostic imaging techniques should be a preoperative standard in diagnostics.

\section{Acknowledgements}

We acknowledge support by Open Access Publication Fund of University of Muenster.

\section{Funding}

This research did not receive any specific grant from funding agencies in the public, commercial or not-for-profit sectors.

\section{Availability of data and materials}

The datasets supporting the conclusions of this article are available at the Department of Cranio-Maxillofacial Surgery, University Hospital Münster Germany.

\section{Authors' contributions}

$\mathrm{MH}$ conceived the study. LFF and JK helped in the acquisition and interpretation of data. MH, LFF and JK participated in literature review, design and drafting of the manuscript. All authors read and approved the final manuscript.

Competing interests

The authors declare that they have no competing interests.

\section{Consent for publication}

Written informed consent was obtained from the patient for publication. A copy of the written consent is available for review by the Editor-in-Chief of this journal.

\section{Ethics approval and consent to participate}

The ethical approval for this study was obtained from the ethical review committee (Ref. no. 2016-474-f-S), Ethikkommission der Ärztekammer Westfalen-Lippe und der Westfälischen Wilhelms-Universität, Münster Germany. Written informed consent to participate was obtained from the patient.

Received: 4 October 2016 Accepted: 29 November 2016 Published online: 06 December 2016 


\section{References}

1. Iglesias-Martin F, Infante-Cossio P, Torres-Carranza E, Prats-Golczer VE, Garcia-Perla-Garcia A. Ectopic third molar in the mandibular condyle: a review of the literature. Med Oral Patol Oral Cir Bucal. 2012;17(6):1013-7.

2. Wang CC, Kok SH, Hou LT, Yang PJ, Lee JJ, Cheng SJ, Kuo RC, Chang HH. Ectopic mandibular third molar in the ramus region: report of a case and literature review. Oral Surg Oral Med Oral Pathol Oral Radiol Endod. 2008; 105(2):155-61.

3. Eklund SA, Pittman JL. Third-molar removal patterns in an insured population. J Am Dent Assoc. 2001;132(4):469-75.

4. Salmerón Jl, del Amo A, Plasencia J, Pujol R, Vila CN. Ectopic third molar in condylar region. Int J Oral Maxillofac Surg. 2008;37(4):398-400.

5. Traiger J, Koral K, Catania AJ, Nathan AS. Impacted third molar and dentigerous cyst of the sigmoid notch of the mandible. Report of a case. Oral Surg Oral Med Oral Pathol. 1965:19:459-61.

6. Granite EL, Isaacs M, Kross JF. Asymptomatic impacted mandibular third molar in the subcondylar-sigmoid notch region associated with extensive sclerotic bone. J Oral Med. 1985;40(2):91-2.

7. Mehta DS, Mehta MJ, Murugesh SB. Impacted mandibular third molar in the sigmoid notch region associated with dentigerous cyst-a case report. J Indian Dent Assoc. 1986;58(12):545-7.

8. Balan N. Tooth in the sigmoid notch. Oral Surg Oral Med Oral Pathol. 1992; 73(6):767.

9. Findık Y, Baykul T. Ectopic third molar in the mandibular sigmoid notch: Report of a case and literature review. J Clin Exp Dent. 2015;7(1):133-7.

10. Adachi M, Motohashi M, Nakashima M, Ehara Y, Azuma M, Muramatsu Y Ectopic Third Molar Tooth at the Mandibular Notch. J Craniofac Surg. 2015; 26(5):455-6.

11. Giardino C, Valletta G. Heterotopia of the lover 3d molar on the level of the sigmoid notch. Clinical case. Arch Stomatol (Napoli). 1966;7(4):323-7.

12. Nishijima K, Kishi K, Komai M, Maeda K, Wake K. A case of impacted third molar and dentigerous cyst located below the sigmoid notch of the mandible. Nihon Koku Geka Gakkai Zasshi. 1976;22(3):391-5.

13. Capelli Jr J. Mandibular growth and third molar impaction in extraction cases. Angle Orthod. 1991;61(3):223-9.

14. Keros J, Susić M. Heterotopia of the mandibular third molar: a case report. Quintessence Int. 1997;28(11):753-4.

15. Toranzo Fernandez M, Terrones Meraz MA. Infected cyst in the coronoid process. Oral Surg Oral Med Oral Pathol. 1992;73(6):768.

16. Thoma KH. Oral Surgery. 3rd ed. St. Louis: C.V. Mosby Co; 1958. p. 538.

17. Stafne EC. Oral Roentgenographic Diagnosis. 4th ed. Philadelphia: W.B. Saunders Co; 1958. p. 51-5.

18. Procacci P, Albanese M, Sancassani G, Turra M, Morandini B, Bertossi D. Ectopic mandibular third molar: report of two cases by intraoral and extraoral access. Minerva Stomatol. 2011;60(7-8):383-90.

19. Ghaeminia H, Meijer GJ, Soehardi A, Borstlap WA, Mulder J, Vlijmen OJ, Bergé SJ, Maal TJ. The use of cone beam CT for the removal of wisdom teeth changes the surgical approach compared with panoramic radiography: a pilot study. Int J Oral Maxillofac Surg. 2011;40(8):834-9.

20. Okuyama K, Sakamoto Y, Naruse T, Kawakita A, Yanamoto S, Furukawa K, Umeda M. Intraoral extraction of an ectopic mandibular third molar detected in the subcondylar region without a pathological cause: A case report and literature review. Cranio. 2016:3:1-5.

\section{Submit your next manuscript to BioMed Central and we will help you at every step:}

- We accept pre-submission inquiries

- Our selector tool helps you to find the most relevant journal

- We provide round the clock customer support

- Convenient online submission

- Thorough peer review

- Inclusion in PubMed and all major indexing services

- Maximum visibility for your research

Submit your manuscript at www.biomedcentral.com/submit 